\title{
BMJ Open What are the effects of ethnicity, sexuality, disability and obesity on the odds of experiencing discrimination among Australian males? A nationwide cross-sectional survey
}

Gregory Armstrong (D) ," Tilahun Haregu, ${ }^{2}$ Jesse Young (D) , ${ }^{3,4}$ Yin Paradies ${ }^{5}$

To cite: Armstrong G, Haregu T, Young J, et al. What are the effects of ethnicity, sexuality, disability and obesity on the odds of experiencing discrimination among Australian males? A nationwide crosssectional survey. BMJ Open 2022;12:e053355. doi:10.1136/ bmjopen-2021-053355

- Prepublication history for this paper is available online. To view these files, please visit the journal online (http://dx.doi. org/10.1136/bmjopen-2021053355).

Received 12 May 2021 Accepted 17 November 2021

Check for updates

(C) Author(s) (or their employer(s)) 2022. Re-use permitted under CC BY-NC. No commercial re-use. See rights and permissions. Published by BMJ.

For numbered affiliations see end of article.

Correspondence to Dr Gregory Armstrong; g.armstrong@unimelb.edu.au

\section{ABSTRACT}

Objectives The global public health community has been slow to acknowledge the important role of discrimination in health inequality. Existing evidence on discrimination is largely based on studies of specific subpopulations and specific forms of discrimination, with limited evidence from general population samples. We assessed the individual and combined effects of ethnicity, sexuality, disability and obesity on the likelihood of discrimination among a general population sample of Australian males.

Design and setting We used data from The Australian Longitudinal Study on Male Health $(n=15988$, with response rate of $35 \%$ ) to estimate the prevalence of selfperceived discrimination within the preceding 2 years and we used binary logistic regression models to assess the individual and combined effects of ethnicity, sexuality, disability and obesity on discrimination.

Participants 13763 adult males were included in this analysis.

Results One in five (19.7\%) males reported experiencing discrimination in the preceding 2 years. Aboriginal and/or Torres Strait Islander males were nearly three times $(0 R=2.97, p<0.001)$ more likely to experience discrimination. Those born in Southern/Eastern Europe, Asia or Africa were at least twice more likely to report discrimination. Homosexual or bisexual males (35.2\%; $\mathrm{OR}=2.23, \mathrm{p}=<0.001)$, men with morbid obesity $(29.2 \%$; $\mathrm{OR}=1.91, \mathrm{p}<0.001)$ and men with a disability $(33.8 \%$; $\mathrm{OR}=2.07, \mathrm{p}<0.001)$ also had higher odds of experiencing discrimination. Those belonging to one $(30.4 \%$; $0 \mathrm{R}=2.60$, $\mathrm{p}<0.001)$ or two or more $(38.2 \% ; 0 \mathrm{R}=3.50, \mathrm{p}<0.001)$ risk groups were increasingly more likely to experience discrimination.

Conclusions Discrimination was correlated with ethnicity, sexuality, obesity and disability. Belonging to two or more of the risk groups was associated with substantial increases in the likelihood of experiencing discrimination. Approaches to preventing discrimination need to acknowledge and address the impact of this intersectionality.

\section{INTRODUCTION}

The global public health community has been slow to acknowledge the important
Strengths and limitations of this study

- This study assessed the individual effects of ethnicity, sexuality, disability and obesity on discrimination in a general population of Australian males.

- This study accounted for the intersectionality of ethnicity, sexuality, disability and obesity in increasing discrimination among Australian males.

- We found that belonging to two or more of the risk groups was associated with substantial increases in the likelihood of experiencing discrimination.

- Data were self-reported and the circumstances of discrimination were not measured in the Ten to Men study.

role of discrimination in health inequality, ${ }^{1}$ defined as "policies, practices and behaviours that perpetuate inequities between socially defined groups'. ${ }^{2}$ Hundreds of millions of people face different forms of discrimination worldwide, carrying the potential for health, social, economic and other harms for individuals, their families and the society at large..$^{3-8}$ To address these challenges, ensuring equality and non-discrimination have been the key principles of the United Nations declaration, ${ }^{9}$ the international human right legal framework and other legal instruments that focus on specific forms of discrimination. ${ }^{10}$

In Australia, discrimination on the basis of ethnicity, disability and sexuality comprise a majority of the complaints received by the Australian Human Rights commission. ${ }^{11}$ Ethnicity has been correlated with discrimination in several countries. For example, high rates of discrimination have been observed among Asian and African American adults in the USA,${ }^{12}$ among people from low income countries living in Southern Europe ${ }^{13}$ and among more than a quarter of immigrants in Norway. ${ }^{14}$ Similarly, Aboriginal and/or Torres 
Strait Islander adults are three times more likely than their non-Indigenous counterparts to experience racism in Australia, ${ }^{15}$ with a broad range of detrimental health effects for Aboriginal and Torres Strait Islander people resulting from exposure to racism. ${ }^{16}$ Furthermore, it has been estimated that perceived racism may explain about a third of the gap in self-reported health status between Aboriginal and Torres Strait Islander and non-indigenous Australians. ${ }^{17}$ There is also evidence that about $14 \%$ of Aboriginal and Torres Strait Islander Australians exhibit avoidance behaviours due to racism. ${ }^{18}$

Disability has also been strongly implicated in experiences of discrimination. A national cross-sectional survey conducted in Australia in 2015 found that about 9\% of people with a disability reported experiencing discrimination related to their disability. ${ }^{19}$ Krnjacki et al found that about $14 \%$ of Australians with a disability reported discrimination in the previous year. Higher rates of discrimination were found among people living in more disadvantaged circumstances indicating intersectionality between disability and area advantage. ${ }^{20}$

Sexual minority groups are also more likely to experience discrimination related to their sexual orientation. For instance, the prevalence of past-year discrimination among Gay men was $50 \%,{ }^{21}$ and is associated with increased odds of depressive symptoms, health inequalities, stress, loneliness and lower quality of life. ${ }^{22} 23$

Emerging evidence suggests that obese people are another group at risk of discrimination. ${ }^{24}$ There are public perceptions that stigmatisation of obesity is reasonable and may trigger individuals to reduce their body weight. But current evidence confirms that weight stigmatisation has negative rather than positive effects on the heath of overweight people, and there have been increased calls for health promotion and other interventions to mitigate this discrimination. ${ }^{25} 26$

Although several studies have quantified exposure to discrimination related to specific causes, ${ }^{27}$ other studies have suggested that some people who experience discrimination can sometimes face difficulties in attributing their experience to a single factor, especially when they may have multiple risk factors for discrimination. ${ }^{28}$ Furthermore, it has been argued that the intersectionality of some social identities or multiple disadvantages could increase the risk of discrimination. ${ }^{29} 30$

As in many countries, the current evidence on the prevalence of discrimination in Australia has limited generalisability as it is largely based on smaller studies from specific subpopulations, without accounting for other sources of discrimination. Although a few studies on the intersectionality of racism and sexual orientation have been conducted, ${ }^{31}$ the combined effects of multiple factors on perceived discrimination have yet to be investigated. Hence, the objectives of this study were to estimate the prevalence of discrimination among Australian males, and to assess the individual and combined effects of ethnicity, sexuality, disability and obesity on perceived discrimination.

\section{MATERIALS AND METHODS}

\section{Data source}

The study population for this study consisted of 13763 males aged between 18 and 55 years who participated in first wave of The Australian Longitudinal Study on Male Health (Ten to Men). This paper presents analysis of data on discrimination collected in 2013-2014 for the baseline wave only, as discrimination was not measured in the subsequent wave of data collection. Details of the cohort profile, study design and data collection methods of the Ten to Men study have been published elsewhere. ${ }^{32}$ In brief, the Ten to Men study used a multi-stage stratified cluster sampling to recruit Australian boys and males from households in Australian Statistical Geographical Standard major city, inner regional and outer regional areas of Australia. A total of 104484 households were approached in 2013 and 2014. From these, 45510 individuals were confirmed to be in-scope for the survey. A total of 15988 (35\%) respondents returned usable data. ${ }^{32}$

In Ten to Men study, the questionnaires for young males aged 15 to 17 years and adults aged $18-55$ years were self-administered, respectively, while the questionnaire for boys aged 10-14 years was completed using a computer-assisted personal interview. Eligible participants were males aged 18-55 years at the time of recruitment, who were Australian citizens or permanent residents and had a sufficient understanding of English to provide informed consent and to complete the questionnaire. Younger people (ie, $<18$ years of age) were not included in our study as they were not asked the discrimination question.

\section{Patient and public involvement}

Patients and the public were not involved in the design, conduct or reporting of this study. We analysed existing data provided by the Australian Institute of Family Studies.

\section{Measurement}

Discrimination

Study participants were asked a single question on how often they have experienced discrimination in the 2 years preceding the survey. They responded on a fivepoint Likert-scale as never, rarely, occasionally, fairly often and very often. For the purpose of this study, participants who reported at least occasionally were considered positive for experiencing discrimination.

\section{Sociodemographic correlates}

We were interested in ethnic minorities, sexual minorities, people with disabilities and people with morbid obesity as potential risk groups for experiencing discrimination. Aboriginal and/or Torres Strait Islander status was determined through participants self-reporting as Aboriginal, Torres Strait Islander or both. Using country and region codes, countries of birth were categorised into (1) Australia and New Zealand; (2) Northwestern Europe; (3) Southern 
and Eastern Europe; (4) Asia; (5) Africa; (6) North America; (7) South Americas and (8) Polynesia. Disability status was assessed using questions from the short set Washington Group on Disability Statistics (WGDS). These questions ask about difficulty in seeing, hearing, walking, remembering/ concentrating, self-care and communicating. A cut-off of 'a lot of difficulty' or 'cannot do at all' recorded for at least one of the core domains was used. ${ }^{33}$ Body mass index (BMI) was calculated using self-reported height and weight. BMI of greater than $35 \mathrm{~kg} / \mathrm{m}^{2}$ (obese class II and III) was considered a sign of morbid obesity. Participants were asked to identify their sexual orientation. While we acknowledge the potential that bisexual and homosexual males may have differing experiences of discrimination, for the purposes of our analyses they were collapsed into one category (ie, bisexual and homosexual males vs other males) to maximise statistical power.

\section{Confounding factors}

All multivariate analyses were adjusted for age, educational status (completed high school or above vs did not complete high school), combined household income before tax and other deductions are taken out ( $\$$ A20 000 or above vs less than $\$$ A20 000 per annum), ${ }^{34}$ employment status (employed vs unemployed) and Socio-Economic Indexes for Areas (SEIFA) of the neighbourhood in which the participant lived. We collapsed SEIFA deciles into two categories, the first decile (ie, neighbourhoods in the bottom $10 \%$ on socioeconomic disadvantage) as one category and deciles $2-10$ as the second category.

\section{Data analysis}

All analyses were conducted using Stata V.16.0 and accounted for the complex multistage sampling design and unequal probability of selection. The sampling weights in the Ten to Men study were calculated as the inverse of the individual probability of selection. ${ }^{35}$ Weighted proportions were used to describe the sociodemographic characteristics of the study participants and the prevalence of discrimination. Binary logistic regression was used to examine ethnic minorities, sexual minorities, people with disabilities and people who are morbidly obesity as minority risk groups for experiencing discrimination, adjusted for age, household income, educational status, employment status and SEIFA. Beta-weights were used to assess the relative importance of the correlates. We also assessed the association between presence of two or more of these factors in an individual and perceived discrimination using logistic regression models.

\section{RESULTS}

\section{Background characteristics of the study population}

The background characteristics of the study participants are shown in table 1. A total of 13763 males aged 18-55 years were included in this study. A quarter $(25.1 \%)$ of the participants were aged between 18 and 29. Less than 1/10 $(8.4 \%)$ had not completed high school education and $15.7 \%$ were unemployed, with $1 / 5(21.2 \%)$ born outside
Table 1 Background characteristics of study participants

$\%(95 \% \mathrm{Cl})$

\begin{tabular}{|lc|}
\hline Age categories & $25.1(24.1$ to 26.1$)$ \\
\hline 18-29 years & $26.7(25.7$ to 27.7$)$ \\
\hline $30-39$ years & $30.6(29.5$ to 31.6$)$ \\
\hline $40-49$ years & $17.6(16.8$ to 18.5$)$ \\
\hline $50-55$ years & \\
\hline Aboriginal and/or Torres Strait Islander & $97.9(97.6$ to 98.1$)$ \\
\hline No & $2.1(1.9$ to 2.4$)$ \\
\hline Yes & \\
\hline Country/Region of birth & $75.7(74.6$ to 76.7$)$ \\
\hline Australia or NZ & $6(5.5$ to 6.6$)$ \\
\hline Northwest Europe & $1.5(1.2$ to 1.8$)$ \\
\hline Southern and Eastern Europe & $12.8(11.9$ to 13.7$)$ \\
\hline Asia & $0.8(0.6$ to 1$)$ \\
\hline North America & $2(1.7$ to 2.4$)$ \\
\hline Africa & $0.4(0.3$ to 0.6$)$ \\
\hline South America & $0.9(0.7$ to 1.1$)$ \\
\hline Polynesia &
\end{tabular}

Language spoken at home

\begin{tabular}{ll} 
Northern European language & $89(88.1$ to 89.8$)$ \\
\hline Other European language & $1.4(1.1$ to 1.7$)$ \\
\hline Southwest and Central Asia & $1.2(0.9$ to 1.5$)$ \\
Southern and Southeast Asia & $6.1(5.5$ to 6.7$)$ \\
Eastern Asian language & $2.1(1.7$ to 2.5$)$ \\
Other languages & $0.3(0.2$ to 0.5$)$
\end{tabular}

\begin{tabular}{lc} 
Highest qualification & \\
Completed High school or above & 91.6 (90.9 to 92.3$)$ \\
\hline Didn't complete high school & $8.4(7.8$ to 9.1$)$
\end{tabular}

Household income

\begin{tabular}{lc}
20000 or above & 96.1 (95.5 to 96.6$)$ \\
Less than 20000 & $3.9(3.4$ to 4.5$)$ \\
Sexual orientation & \\
Heterosexual & $92.8(92.1$ to 93.4$)$ \\
Homo/bisexual & $3.5(3.1$ to 4$)$ \\
Not sure & $2.1(1.8$ to 2.5$)$ \\
Others & $1.6(1.3$ to 1.9$)$ \\
Body mass index & \\
\hline Underweight & $0.6(0.5$ to 0.9$)$ \\
\hline Normal weight & $34.6(33.4$ to 35.8$)$ \\
\hline Overweight & $42.6(41.4$ to 43.8$)$ \\
\hline Moderate obesity & $15(14.3$ to 15.9$)$ \\
\hline Morbid Obesity & $7.2(6.6$ to 7.8$)$ \\
Disability: WGDS & \\
\hline Without disability & $93.2(92.6$ to 93.7$)$ \\
\hline With disability & $6.8(6.3$ to 7.4$)$ \\
SEIFA decile & \\
\hline Second decile and above & $90.4(89.5$ to 91.2$)$ \\
First decile & $9.7(8.9$ to 10.5$)$ \\
\hline
\end{tabular}

Continued 


\section{Table 1 Continued}

$\%(95 \% \mathrm{Cl})$

\begin{tabular}{ll}
\hline Employment status & \\
\hline Employed & $84.3(83.4$ to 85.2$)$ \\
\hline Unemployed & $15.7(14.8$ to 16.6$)$ \\
\hline Discrimination & \\
\hline No & $80.3(79.4$ to 81.3$)$ \\
Yes & $19.7(18.8$ to 20.6$)$ \\
\hline
\end{tabular}

NZ, New Zealand; SEIFA, Socio-Economic Indexes for Areas; WGDS, Washington Group Disability Score.

Australia or New Zealand. A minority of participants identified themselves as Aboriginal and/or Torres Strait Islander $(2.6 \%)$ or homosexual or bisexual $(3.4 \%)$, with $6.1 \%$ being morbidly obese and $6.8 \%$ having a disability.

\section{Prevalence of discrimination}

Nearly one in five males $(19.7 \%)$ had experienced discrimination; $6.2 \%$ very often or fairly often and $13.5 \%$ occasionally. More than half $(51.4 \%)$ had never experienced discrimination and $28.9 \%$ experienced discrimination rarely.

\section{Correlates of discrimination}

After adjusting for model covariates, Aboriginal and/ or Torres Strait Islander males had three times higher odds $(\mathrm{OR}=2.97)$ of reporting perceived discrimination than non-Indigenous males. Males born in Asia $(\mathrm{OR}=3.28)$, Africa $(\mathrm{OR}=2.78)$ and Southern/Eastern Europe $(\mathrm{OR}=2.20)$ had significantly higher odds of experiencing discrimination compared with those born in Australia or New Zealand (all $\mathrm{p}<0.001$ ); South America as country of birth approached statistical significance $(\mathrm{OR}=2.05, \mathrm{p}=0.053)$, and our study may have been underpowered for this sub-group. Homosexual and bisexual males had more than two times $(\mathrm{OR}=2.23)$ the odds of experiencing discrimination than heterosexual males. Males with disability $(\mathrm{OR}=2.07)$ and males with morbidly obesity (OR=1.91) had two times higher odds of experiencing discrimination. Based on beta-weights, country of birth was found to be the strongest correlate. Details of correlates of discrimination are shown in table 2.

\section{Intersectionality of correlates}

We sought to explore the association between of presence of two or more of the five risk factors in an individual on perceived discrimination (see table 3). The majority $(73.5 \%)$ of males belonged to none of the five risk groups. About a quarter $(23.6 \%)$ belonged to any one of the five risk groups and $2.7 \%$ belonged to any two. The remaining $0.2 \%$ belonged to three or more of the five risk groups. The number of risk groups an individual belonged to was significantly associated with increasing odds of discrimination, rising from an OR of 2.6 for males belonging to one risk group to an OR of 3.5 for males belonging to two or more risk groups. The predicted probabilities of discrimination among males with none, one and two or more risk factors was $14.1 \%, 29.8 \%$ and $38.0 \%$, respectively.

The highest effect for belonging to a single risk group only was for Aboriginal and Torres Strait Islander status $(\mathrm{OR}=3.63)$ followed by country of birth $(\mathrm{OR}=3.06)$ and homosexuality/bisexuality $(\mathrm{OR}=3.01)$.

\section{DISCUSSION}

Our findings indicate that discrimination is positively associated with ethnicity, disability, obesity and sexual orientation. A strong compounding effect was observed for membership of two or more risk groups, with the odds rising with membership to each additional group.

Our findings of higher odds of perceived discrimination among Aboriginal and/or Torres Strait Islander males are consistent with the findings of other studies conducted in Australia. For instance, a study of experiences of racism among Aboriginal and Torres Strait Islander adults living in the Australian state of Victoria found that Aboriginal and Torres Strait Islander adults had three time higher odds of experiencing racism in the preceding 12 months and another study reported a higher prevalence of vicarious discrimination among Aboriginal and/or Torres Strait Islander primary carers of children. ${ }^{15} 36$ Our findings related to country of birth are also consistent with prior research examining discrimination experienced by culturally and linguistically diverse communities. ${ }^{37}$ Similarly, our findings on the high prevalence of discrimination experienced by sexual minorities, people with disabilities, and people who are morbidly obese are also consistent with other studies. ${ }^{19} 24273839$

By considering the combined effects of multiple risk factors, our study has also demonstrated an increased risk of discrimination with an increasing number of factors. We observed that membership in two or more of the examined risk groups increased the risk of perceived discrimination by a considerable magnitude. Recent studies have given attention to assessing intersectionality of multiple attributes of discrimination and the effect of that intersectionality on health and well-being. ${ }^{29} 314041$ Such studies highlight that sources of discrimination can be multiple and intertwined in complex ways. For example, research in Australia has examined the complex experiences of sexual minorities who are also Aboriginal and Torres Strait Islander people or people from culturally and linguistically diverse backgrounds, and faced 'bad encounters' shaped by race, gender and sexuality. ${ }^{42}$ That is, some sexual minorities may experience discrimination from within their Aboriginal and Torres Strait Islander communities in relation to their sexuality, while also experiencing discrimination from non-Indigenous Australians in a 'gay pub' in relation to their ethnicity. What is clear, is that policies and programmes related to the prevention of discrimination need to engage 
Table 2 Correlates of perceived discrimination in the preceding 2 years among Australian males

Prevalence of
discrimination $\%(95 \%$

$\begin{array}{llllll}\text { discrimination } \%(95 \% & \text { OR }(95 \% \mathrm{Cl}) & \text { P value } & \text { OR }(95 \% \mathrm{Cl}) & \text { P value } & \text { B-weight }\end{array}$

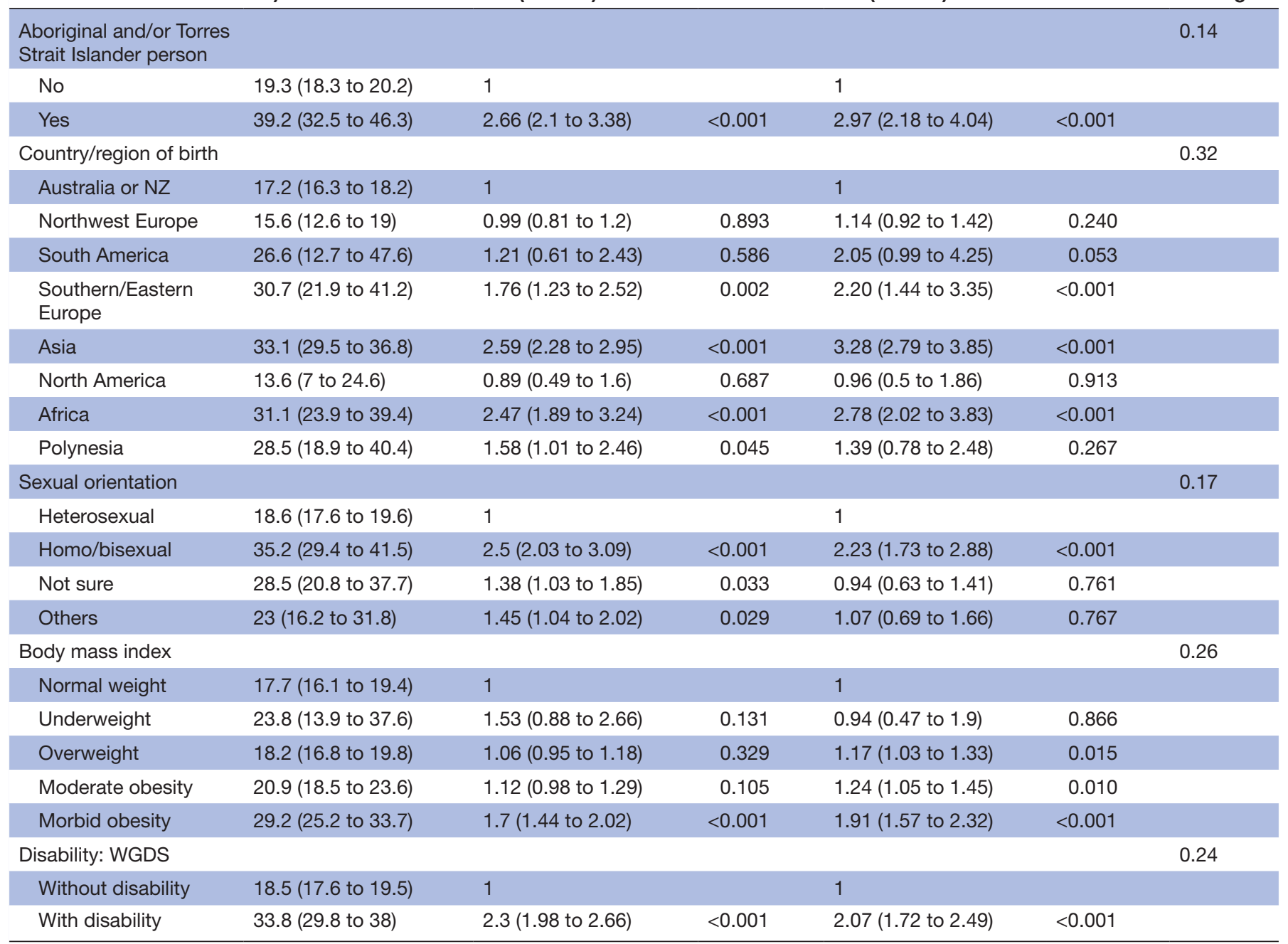

*Adjusted for age, educational status, household income, SEIFA and employment status.

NZ, New Zealand; SEIFA, Socio-Economic Indexes for Areas; WGDS, Washington Group on Disability Statistics.

with this intersectionality and address the substantially increased risk of discrimination from belonging to more than one risk group. Future research should also investigate the combined effect of these factors on health and other outcomes.

Our study is unique as we used a very large sample of males from the general population, presenting a unique opportunity to examine the prevalence of discrimination across a range of risk groups and the combined effects from membership to multiple risk groups. Nonetheless, there are some limitations associated with this study. The Ten to Men data were selfreported and there could be a possibility of recall bias or social desirability bias during the assessment of discrimination and associated risk factors. Discrimination was measured by a single question and data on the circumstances and other characteristics related to the discrimination were not collected, including what characteristic the discrimination could be attributed to and who the perpetrator(s) was. Additionally, while some experiences of discrimination may be interpersonal and more obvious, others may be institutional and invisible, ${ }^{5}$ resulting in under-reporting by participants. Disability was measured by the WGDS short set which may not fully capture people with disabilities related to mental health. Due to some sample limitations, we were not able to address a range of other factors that may increase the risk of experiencing discrimination (eg, older age). The study findings are generalisable only to regional and urban centres and males' experiences.

\section{CONCLUSION}

Discrimination was positively associated with ethnicity, disability, obesity and sexual orientation. A strong compounding effect was observed for membership of 


\begin{tabular}{|c|c|c|c|c|c|c|}
\hline & \multirow[b]{3}{*}{ N (\%) } & \multicolumn{4}{|c|}{ Discrimination } & \multirow[b]{3}{*}{$P$ value } \\
\hline & & \multicolumn{2}{|c|}{ Prevalence } & \multicolumn{2}{|r|}{ OR } & \\
\hline & & Per cent & $95 \% \mathrm{Cl}$ & OR & $95 \% \mathrm{Cl}$ & \\
\hline None (ref) & $11653(75.7)$ & 14.4 & 13.5 to 15.4 & 1.00 & & \\
\hline Aboriginal and/or TSI only & $343(2.2)$ & 36.1 & 28.6 to 44.3 & 3.63 & 2.64 to 5.00 & $<0.001$ \\
\hline Disability only & $717(4.7)$ & 29.4 & 24.8 to 34.3 & 2.25 & 1.84 to 2.75 & $<0.001$ \\
\hline Morbid obesity only & $728(4.7)$ & 24.9 & 20.6 to 29.8 & 1.75 & 1.43 to 2.13 & $<0.001$ \\
\hline \multicolumn{7}{|l|}{ No of risk groups } \\
\hline None (ref) & $11653(73.5)$ & 14.4 & 13.5 to 15.4 & 1.00 & & \\
\hline
\end{tabular}

${ }^{*}$ Adjusted for age, educational status, household income, SEIFA and employment status.

${ }^{\star \star}$ Born in Southern and Eastern Europe/Asia/Africa.

SEIFA, Socio-Economic Indexes for Areas.

two or more risk groups, with the likelihood rising with membership to each additional group. Policies and programmes related to the prevention of discrimination may benefit from engaging with this intersectionality and addressing the substantially increased risk of discrimination from belonging to more than one risk group.

\section{Author affiliations}

${ }^{1}$ The University of Melbourne School of Population and Global Health, Melbourne, Victoria, Australia

${ }^{2}$ Melbourne School of Population and Global Health, University of Melbourne, Melbourne, Victoria, Australia

${ }^{3}$ Centre for Health Equity, The University of Melbourne School of Population and Global Health, Melbourne, Victoria, Australia

${ }^{4}$ Centre for Adolescent Health, Murdoch Childrens Research Institute, Parkville, Victoria, Australia

${ }^{5}$ Deakin University Alfred Deakin Institute for Citizenship and Globalisation, Burwood, Victoria, Australia

\section{Twitter Gregory Armstrong @googarmstrong}

Acknowledgements The author(s) disclosed receipt of the following financial support for the research, authorship and/or publication of this article: The research on which this paper is based was conducted as part of the Australian Longitudinal Study on Male Health (Ten to Men). We are grateful to the Australian Government Department of Health for funding and to the boys and men who provided the survey data. Ten to Men is managed by the Australian Institute of Family Studies. Ten to Men research data is the intellectual property of the Commonwealth.

Contributors GA and TH conceptualised the study, conducted the data analysis and wrote the first draft of the manuscript. JY and YP provided substantial inputs into reviewing the analyses and editing the manuscript. All authors have read and approved the manuscript for submission. GA accepts full responsibility for the overall content as the guarantor of this work.

Funding The Australian Longitudinal Study on Male Health (Ten to Men) was funded by the Australian Government Department of Health. GA is funded by an Early Career Fellowship from the National Health and Medical Research Council (GNT1138096). JY receives salary and research support from a National Health and Medical Research Council Investigator Grant (GNT1178027).

Competing interests None declared.
Patient and public involvement Patients and/or the public were not involved in the design, or conduct, or reporting, or dissemination plans of this research.

Patient consent for publication Not applicable.

Ethics approval The Ten to Men study obtained ethical clearance from the University of Melbourne Human Sciences Human Ethics Sub-Committee (HREC 1237897 and 1237376).

Provenance and peer review Not commissioned; externally peer reviewed.

Data availability statement Data may be obtained from a third party and are not publicly available. Deidentified data are available from the Ten to Men Data Management team at the Australian Institute of Family Studies, who the custodians of the Australian Longitudinal Study on Male Health: ttmdatamanager@aifs.gov.au.

Open access This is an open access article distributed in accordance with the Creative Commons Attribution Non Commercial (CC BY-NC 4.0) license, which permits others to distribute, remix, adapt, build upon this work non-commercially, and license their derivative works on different terms, provided the original work is properly cited, appropriate credit is given, any changes made indicated, and the use is non-commercial. See: http://creativecommons.org/licenses/by-nc/4.0/.

ORCID iDs

Gregory Armstrong http://orcid.org/0000-0002-8073-9213

Jesse Young http://orcid.org/0000-0001-5702-372X

\section{REFERENCES}

1 Gulliford M. Discrimination and public health. Lancet Public Health 2019;4:e173-4.

2 Scheim Al, Bauer GR. The intersectional discrimination index: development and validation of measures of self-reported enacted and anticipated discrimination for intercategorical analysis. Soc Sci Med 2019;226:225-35.

3 International Labour Organization. ILO: workplace discrimination, a picture of hope and concern. world of work Maganzine No.47, 2003.

4 Krieger N. Discrimination and health inequities. Int $J$ Health Serv 2014;44:643-710.

5 Krieger N. Embodying inequality: a review of concepts, measures, and methods for studying health consequences of discrimination. Int $J$ Health Serv 1999;29:295-352.

6 Lockwood KG, Marsland AL, Matthews KA, et al. Perceived discrimination and cardiovascular health disparities: a multisystem review and health neuroscience perspective. Ann N Y Acad Sci 2018;1428:170-207. 
7 Schmitt MT, Branscombe NR, Postmes T, et al. The consequences of perceived discrimination for psychological well-being: a metaanalytic review. Psychol Bull 2014;140:921-48.

8 Haregu T, Jorm AF, Paradies Y, et al. Discrimination experienced by Aboriginal and Torres Strait Islander males in Australia: associations with suicidal thoughts and depressive symptoms. Aust N Z J Psychiatry 2021:000486742110311.

9 United Nations. Declaration on the elimination of all forms of intolerance and of discrimination based on religion or belief. New York, USA: UN, 1981.

10 United Nations. Equality and Non-discrimination. UN: United Nations and the Rule of Law.

11 Australian Human Rights Commission. 2017 - 2018 complaint statistics. Sydney, Australia, 2019

12 Brondolo E, Rahim R, Grimaldi S, et al. Place of birth effects on self-reported discrimination: variations by type of discrimination. Int $J$ Intercult Relat 2015;49:212-22.

13 Borrell C, Muntaner C, Gil-González D, et al. Perceived discrimination and health by gender, social class, and country of birth in a southern European country. Prev Med 2010;50:86-92.

14 Straiton ML, Aambø AK, Johansen R. Perceived discrimination, health and mental health among immigrants in Norway: the role of Moderating factors. BMC Public Health 2019;19:325.

15 Markwick A, Ansari Z, Clinch D, et al. Experiences of racism among Aboriginal and Torres Strait Islander adults living in the Australian state of Victoria: a cross-sectional population-based study. BMC Public Health 2019;19:309.

16 Paradies Y. Racism and Indigenous Health. In: Oxford research encyclopedia of global public health, 2018.

17 Markwick A, Ansari Z, Clinch D, et al. Perceived racism may partially explain the gap in health between Aboriginal and non-Aboriginal Victorians: a cross-sectional population based study. SSM Popul Health 2019;7:100310-10.

18 Temple JB, Kelaher M, Paradies Y. Prevalence and context of racism experienced by older Aboriginal and Torres Strait Islanders. Australas $J$ Ageing 2019;38:39-46.

19 Temple JB, Kelaher M, Williams R. Discrimination and avoidance due to disability in Australia: evidence from a national cross sectional survey. BMC Public Health 2018;18:1347.

20 Krnjacki L, Priest N, Aitken Z, et al. Disability-based discrimination and health: findings from an Australian-based population study. Aust N Z J Public Health 2018:42:172-4.

21 Bostwick WB, Boyd CJ, Hughes TL, et al. Discrimination and mental health among lesbian, gay, and bisexual adults in the United States. Am J Orthopsychiatry 2014;84:35-45.

22 Jackson SE, Hackett RA, Grabovac I, et al. Perceived discrimination, health and wellbeing among middle-aged and older lesbian, gay and bisexual people: a prospective study. PLoS One 2019;14:e0216497.

23 Zeeman L, Sherriff N, Browne K, et al. A review of lesbian, gay, bisexual, trans and intersex (LGBTI) health and healthcare inequalities. Eur J Public Health 2019;29:974-80.

24 Spooner C, Jayasinghe UW, Faruqi N, et al. Predictors of weight stigma experienced by middle-older aged, general-practice patients with obesity in disadvantaged areas of Australia: a cross-sectional study. BMC Public Health 2018;18:640.

25 Puhl RM, Heuer CA. Obesity stigma: important considerations for public health. Am J Public Health 2010;100:1019-28.

26 Puhl R, Suh Y. Health consequences of weight stigma: implications for obesity prevention and treatment. Curr Obes Rep 2015;4:182-90.
27 Emerson E, Milner A, Aitken Z, et al. Exposure to discrimination and subsequent changes in self-rated health: prospective evidence from the UK's life opportunities survey. Public Health 2020;185:176-81.

28 Harnois CE, Bastos JL, Shariff-Marco S. Intersectionality, contextual specificity, and everyday discrimination: assessing the difficulty associated with identifying a main reason for discrimination among racial/ethnic minority Respondents. Sociol Methods Res;140:004912412091492.

29 Vu M, Li J, Haardörfer R, et al. Mental health and substance use among women and men at the intersections of identities and experiences of discrimination: insights from the intersectionality framework. BMC Public Health 2019;19:108.

30 Bowleg L. The problem with the phrase women and minorities: intersectionality-an important theoretical framework for public health. Am J Public Health 2012;102:1267-73.

31 Bastos JL, Harnois CE, Paradies YC. Health care barriers, racism, and intersectionality in Australia. Soc Sci Med 2018;199:209-18.

32 Pirkis J, Currier D, Carlin J, et al. Cohort profile: ten to men (the Australian longitudinal study on male health). Int $\mathrm{J}$ Epidemiol 2017;46:793-4

33 Madans JH, Loeb ME, Altman BM. Measuring disability and monitoring the un convention on the rights of persons with disabilities: the work of the Washington group on disability statistics. BMC Public Health 2011;11 Suppl 4:S4.

34 Korda RJ, Paige E, Yiengprugsawan V, et al. Income-Related inequalities in chronic conditions, physical functioning and psychological distress among older people in Australia: crosssectional findings from the 45 and up study. BMC Public Health 2014;14:741.

35 Spittal MJ, Carlin JB, Currier D, et al. The Australian longitudinal study on male health sampling design and survey weighting: implications for analysis and interpretation of clustered data. BMC Public Health 2016;16:1062.

36 Shepherd CCJ, Li J, Cooper MN, et al. The impact of racial discrimination on the health of Australian Indigenous children aged 5-10 years: analysis of national longitudinal data. Int J Equity Health 2017; $16: 116$.

37 Ferdinand AS, Paradies Y, Kelaher M. Mental health impacts of racial discrimination in Australian culturally and linguistically diverse communities: a cross-sectional survey. BMC Public Health 2015:15:401.

38 Lee JH, Gamarel KE, Bryant KJ, et al. Discrimination, mental health, and substance use disorders among sexual minority populations. LGBT Health 2016;3:258-65.

39 Hunte HER, Williams DR. The association between perceived discrimination and obesity in a population-based multiracial and multiethnic adult sample. Am J Public Health 2009;99:1285-92.

40 Seaton EK, Caldwell CH, Sellers RM, et al. An intersectional approach for understanding perceived discrimination and psychological well-being among African American and Caribbean black youth. Dev Psychol 2010;46:1372-9.

41 Reisen CA, Brooks KD, Zea MC, et al. Can additive measures add to an intersectional understanding? experiences of gay and ethnic discrimination among HIV-positive Latino gay men. Cultur Divers Ethnic Minor Psychol 2013;19:208-17.

42 Ruez D. "I never felt targeted as an Asian ... until I went to a gay pub": Sexual racism and the aesthetic geographies of the bad encounter. Environ Plan A 2017;49:893-910. 